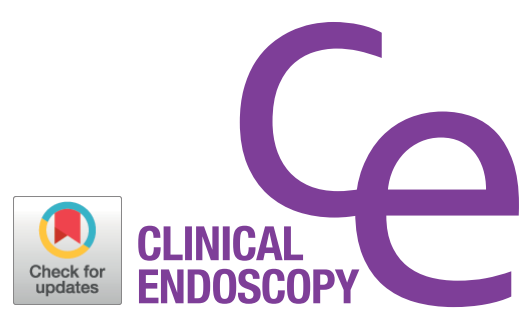

\title{
White Bile in Malignant Biliary Obstruction: A Poor Prognostic Marker
}

\author{
Anas Gremida and Tarun Rustagi \\ Division of Gastroenterology and Hepatology, Department of Internal Medicine, University of New Mexico, Albuquerque, NM, USA
}

A 71-year-old man presented with progressively worsening painless jaundice. Laboratory findings were significant for severe cholestasis (serum total bilirubin, $24 \mathrm{mg} / \mathrm{dL}$; direct bilirubin, $22 \mathrm{mg} / \mathrm{dL}$ ). Computed tomography of the abdomen revealed a $4-\mathrm{cm}$ mass in the head of the pancreas with marked extra- and intra-hepatic biliary dilatation (Fig. 1A). Diffuse hepatic metastases and extensive metastatic retroperitoneal and left supraclavicular adenopathy were also noted (Fig. 1B). Endoscopic ultrasound (EUS) revealed a $32 \times 28 \mathrm{~mm}$ hypoechoic heterogeneous solid mass in the head of the pancreas, causing complete obstruction of the common bile duct, with marked upstream ductal dilation (Fig. 2A). EUS-guided fine needle aspiration cytology revealed a poorly differentiated pancreatic adenocarcinoma. Endoscopic retrograde cholangiopancreatography for transpapillary biliary stenting was unsuccessful. Subsequently, EUS-guided choledochoduodenostomy using a $15-10 \mathrm{~mm}$, cautery-tipped, biflanged, fully covered, lumen-apposing
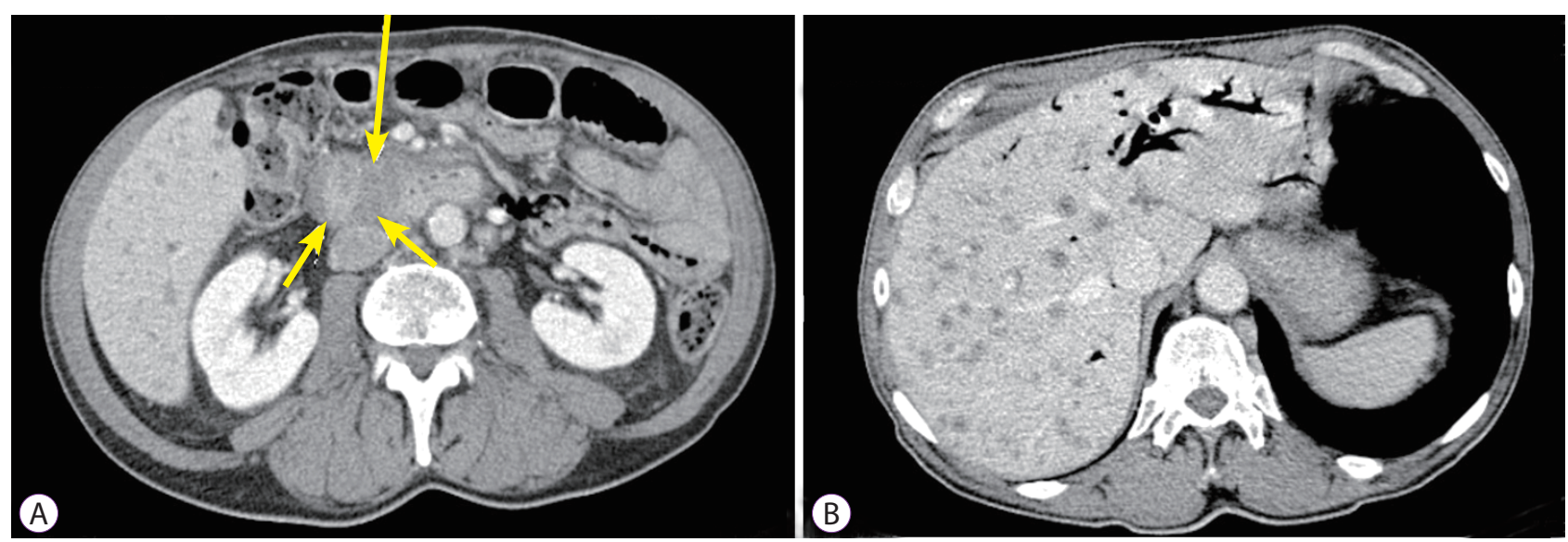

Fig. 1. Computed tomography scan of the abdomen indicating an infiltrating mass in the head of the pancreas (arrows) (A) and numerous hepatic metastatic lesions (B).

Received: July 6, 2017 Revised: July 31, 2017 Accepted: August 1, 2017

Correspondence: Tarun Rustagi

Division of Gastroenterology and Hepatology, Department of Internal Medicine, University of New Mexico, MSC10 5550, Albuquerque, NM 87131, USA

Tel: +1-860-221-4034, Fax: +1-505-272-9751, E-mail: tarunrustagi06@gmail.com

(cc) This is an Open Access article distributed under the terms of the Creative Commons Attribution Non-Commercial License (http://creativecommons.org/ licenses/by-nc/3.0) which permits unrestricted non-commercial use, distribution, and reproduction in any medium, provided the original work is properly cited. metal stent (LAMS, Hot AXIOS; Boston Scientific, Marlborough, MA, USA), was performed resulting in the drainage of the colorless "white" bile (Figs. 2B, 3, Video 1).

White bile is a colorless fluid devoid of pigments, bile salts, and cholesterol found in an occluded biliary system. Decolorization of the bile in an obstructed biliary system occurs because the biliary epithelium continues to secrete mucus 

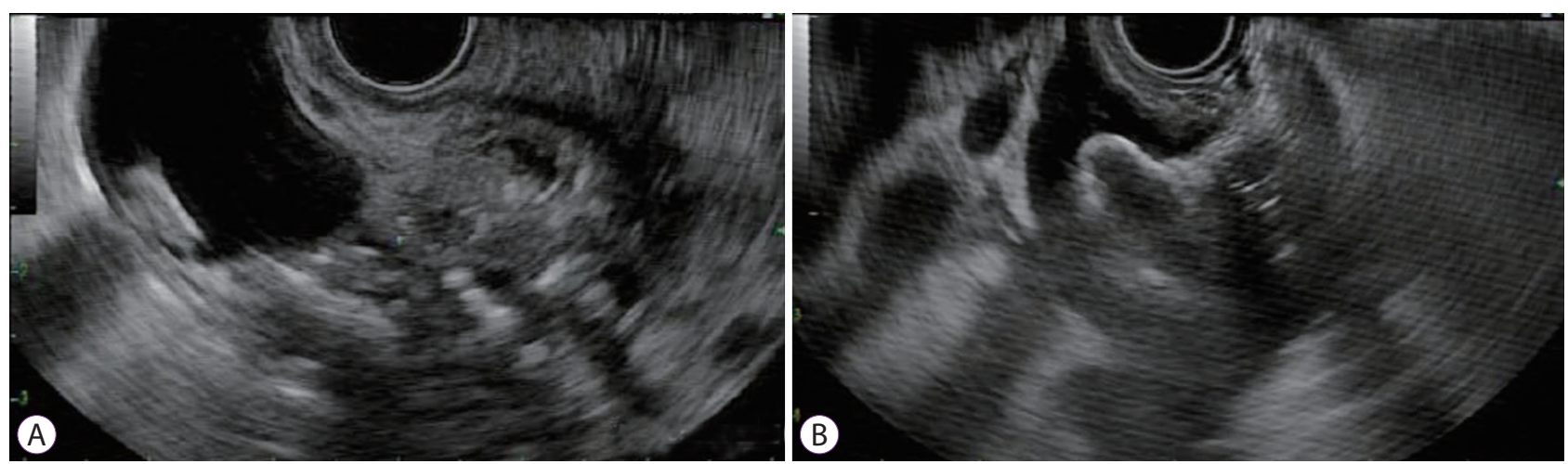

Fig. 2. Endoscopic ultrasound indicating a solid mass in the head of the pancreas, causing complete obstruction and marked dilation of the upstream bile duct (A). A transduodenal AXIOS (Boston Scientific, Marlborough, MA, USA) stent placed into the dilated bile duct, creating an endoscopic choledochoduodenostomy (B).

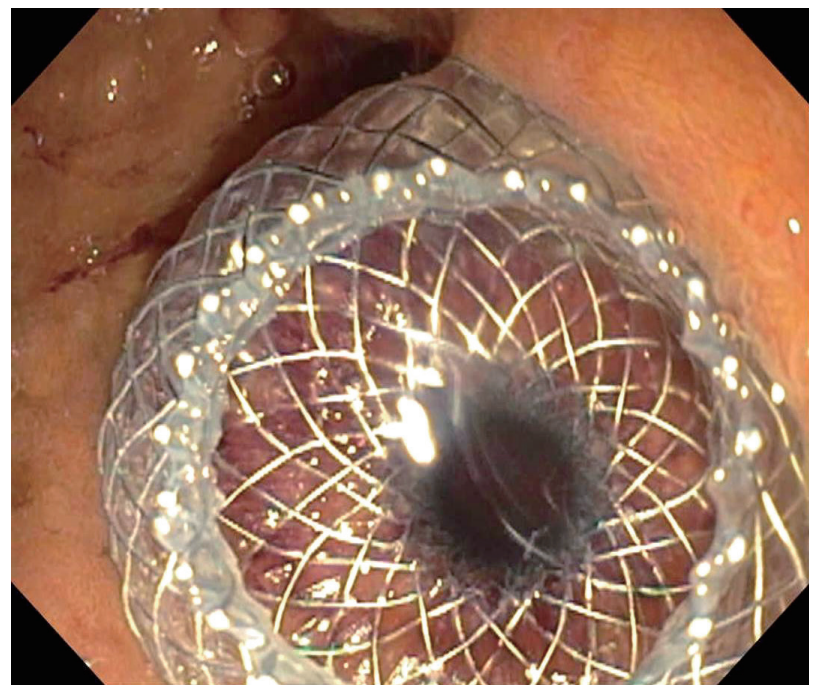

Fig. 3. Endoscopic appearance of the colorless "white" bile in the duodenum.

in stagnant bile. As a result, the bile becomes increasingly lighter in color, and eventually, colorless. This can only occur when there is a loss of communication with the gallbladder, as in cholecystectomy, in an obstructed cystic duct, obstruction above the level of the cystic duct, or non-functioning gallbladder (gallbladder hydrops). On the contrary, if the ob- structed biliary duct is in communication with a functioning gallbladder, this will result in a more concentrated bile of darker color, known as "black bile". Patients with white bile have a predisposition to infection due to ineffective drainage and reduced antimicrobial activity. Furthermore, the finding of white bile in malignant jaundice has been associated with shorter survival than that in patients with green bile.

\section{Conflicts of Interest}

The authors have no financial conflicts of interest.

\section{Supplementary Material}

Video 1. Endoscopy showing drainage of the colorless "white" bile through an endoscopic ultrasound-guided choledochoduodenostomy metal stent (https://doi.org/10.5946/ce.2017.111.v001).

\section{REFERENCES}

1. Hashmonai M, Kam I, Schramek A. The etiology of "white bile" in the biliary tree. J Surg Res 1984;37:479-486.

2. Ahuja V, Garg PK, Kumar D, Goindi G, Tandon RK. Presence of white bile associated with lower survival in malignant biliary obstruction. Gastrointest Endosc 2002;55:186-191.

3. Geraci G, Sciumè C, Pisello F, Li Volsi F, Facella T, Modica G. Presence of white bile in malignant biliary obstruction is associated with poor prognosis: personal preliminary observations. Langenbecks Arch Surg 2007;392:61-65. 